\section{Commentary: Atrial fibrillation after cardiac surgery: More than just a nuisance!}

\author{
Syed T. Hussain, MD, and Robert Kalimi, MD
}

New-onset postoperative atrial fibrillation (POAF) is not benign and adversely affects postoperative outcomes and survival. POAF is associated with increased perioperative death, stroke, heart failure, and acute renal failure and significantly increases the length of hospital stay, readmission risk, and resource utilization. ${ }^{1-5}$

In this issue of the Journal, Caldonazo and colleagues ${ }^{6}$ provide the latest, detailed evidence of both short- and long-term adverse consequences of POAF. They performed a systematic review and meta-analysis of 57 studies (246,340 patients) to address the impact of POAF, focusing on all classic cardiovascular adverse events during the perioperative period as well as in long-term follow up. Consistent with the recent literature, POAF was associated with increased risk of postoperative mortality, stroke, myocardial infarction, acute renal failure, hospital, and intensive care unit stay. In addition, POAF was associated with increased long-term mortality, stroke, and, very significantly, long-standing persistent atrial fibrillation (incidence rate ratio, 4.73).

Despite the lack of an adequate control group, a potentially heterogenous study population, the possibility of including patients with preexisting atrial fibrillation, and possibly varying definitions of outcomes among publications, the study has many strengths. Apart from analyzing all important cardiovascular events and including more than 200,000 additional patients from contemporary publications, the authors have also performed subgroup analyses to evaluate the effect of time of publication (before or after

\footnotetext{
From the Donald and Barbara Zucker School of Medicine at Hofstra/Northwell, Hempstead, NY and Department of Cardiovascular and Thoracic Surgery, Northwell Health/South Shore University Hospital, Bay Shore, NY.

Disclosures: The authors reported no conflicts of interest.

The Journal policy requires editors and reviewers to disclose conflicts of interest and to decline handling or reviewing manuscripts for which they may have a conflict of interest. The editors and reviewers of this article have no conflicts of interest.

Received for publication March 29, 2021; revisions received March 29, 2021; accepted for publication March 30, 2021; available ahead of print April 12, 2021.

Address for reprints: Syed T. Hussain, MD, Department of Cardiovascular \& Thoracic Surgery, Northwell Health/South Shore University Hospital, 301 East Main St, Bayshore, NY 11706 (E-mail: shussain8@ northwell.edu).

J Thorac Cardiovasc Surg 2023;165:106-7

0022-5223/\$36.00

Copyright (c) 2021 by The American Association for Thoracic Surgery

https://doi.org/10.1016/j.jtcvs.2021.03.104
}

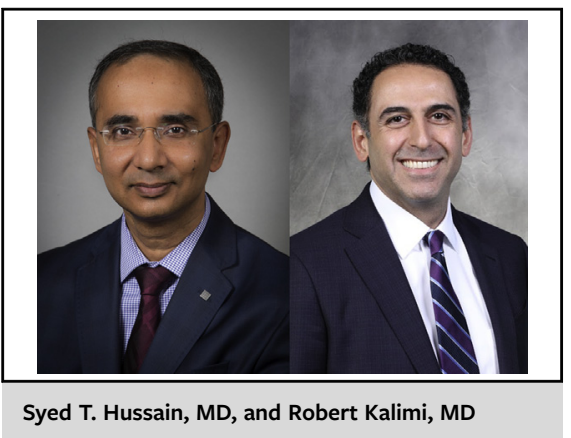

\begin{abstract}
CENTRAL MESSAGE
Atrial fibrillation after cardiac

surgery is not benign and is

associated with significant short-

and long-term adverse conse-

quences, including increased

mortality, stroke, and resource

utilization.
\end{abstract}

2010), the method used to detect POAF, and type of surgery. They also performed meta-regression to measure the effects of 12 different preoperative factors on outcome, and leaveone-out analysis to confirm the solidity of the pooled estimate. Although there are recent publications on POAF, these either analyzed few outcomes or did not include some of the important contemporary publications. ${ }^{3}$ The current article provides the most up-to-date and comprehensive information on the deleterious effects of POAF. Most importantly, this study validates the persistent risk that POAF represents in the long term, including persistent atrial fibrillation.

While this study does not provide a direct causal relationship between POAF and the adverse outcomes or whether it was only a marker of increased cardiovascular risk, it provides impetus for continued research into risks factors for POAF, and the most effective management strategy both for prevention and treatment. This is crucial, given the magnitude of this problem, as shown by the authors and from recent Society of Thoracic Surgeons database analysis where rate of POAF was $23 \%-42 \%$, depending on the type of surgery. ${ }^{5}$ Although much research has focused on the prevention of POAF, effective intervention strategies are still lacking. Similarly, there is lack of consensus regarding the management of POAF, which includes rate control and rhythm control strategies. In a recent randomized Cardiothoracic Surgical Trial Network trial involving 23 
US centers, neither rate nor rhythm control strategies showed a net clinical advantage over the other. ${ }^{4}$ Current management strategies also result in treatment-related adverse events including bleeding, thromboembolic complications, and drug-related toxicity.

The most important take-home message from this study should be a change in the mindset of managing POAF from just a transient nuisance to being an important risk factor for both short- and long-term morbidity and mortality.

\section{References}

1. Badhwar V, Rankin JS, Damiano RJ Jr, Gillinov AM, Bakaeen FG, Edgerton JR, et al. The Society of Thoracic Surgeons 2017 clinical practice guidelines for the surgical treatment of atrial fibrillation. Ann Thorac Surg. 2017;103:329-41.
2. January CT, Wann LS, Alpert JS, Calkins H, Cigarroa JE, Cleveland JC Jr, et al 2014 AHA/ACC/HRS guideline for the management of patients with atrial fibrillation: a report of the American College of Cardiology/American Heart Association task force on practice guidelines and the Heart Rhythm Society. J Am Coll Cardiol. 2014;64:e1-76.

3. Eikelboom R, Sanjanwala R, Le ML, Yamashita MH, Arora RC. Postoperative atrial fibrillation after cardiac surgery: a systematic review and meta-analysis. Ann Thorac Surg. 2021;111:544-54.

4. Gillinov AM, Bagiella E, Moskowitz AJ, Raiten JM, Groh MA, Bowdish ME, et al; CTSN. Rate control versus rhythm control for atrial fibrillation after cardiac surgery. N Engl J Med. 2016;374:1911-21.

5. Fernandez FG, Shahian DM, Kormos R, Jacobs JP, D'Agostino RS, Mayer JE Jr, et al. The Society of Thoracic Surgeons National database 2019 annual report. Ann Thorac Surg. 2019;108:1625-32.

6. Caldonazo T, Kirov H, Rahouma M, Robinson NB, Demetres M, Gaudino M, et al Atrial fibrillation after cardiac surgery: a systematic review and meta-analysis. J Thorac Cardiovasc Surg. 2023;165:94-103.e24. 